\title{
Knowledge and Attitude regarding COVID-19 among Pregnant Women in Southwestern Iran in the Early Period of its Outbreak: A Cross-Sectional Study
}

\author{
Najmeh Maharlouei, ${ }^{1}$ Nasrin Asadi, ${ }^{2}$ Khadijeh Bazrafshan, ${ }^{2}$ Shohreh Roozmeh, ${ }^{2}$ Abbas Rezaianzadeh, ${ }^{3}$ \\ Mohammad-hassan Zahed-roozegar, ${ }^{1}$ Fatemeh Shaygani, ${ }_{1}^{1}$ Ali Kharmandar, ${ }^{1,4}$ Behnam Honarvar, ${ }^{1}$ Camellia Hemyari, ${ }^{1}$ \\ Navid Omidifar, ${ }^{5}$ Marziyeh Zare, ${ }^{1}$ and Kamran B. Lankarani ${ }^{1 *}$ \\ ${ }^{1}$ Health Policy Research Center, Institute of Health, Shiraz University of Medical Sciences, Shiraz, Iran; ${ }^{2}$ Maternal-Fetal Medicine Research Center, \\ Shiraz University of Medical Sciences, Shiraz, Iran; ${ }^{3}$ Colorectal Research Center, Shiraz University of Medical Sciences, Shiraz, Iran; ${ }^{4}$ Non- \\ Communicable Disease Research Center, Fasa University of Medical Sciences, Fasa, Iran; ${ }^{5}$ Department of Pathology, Medical Education Research \\ Center, Shiraz University of Medical Sciences, Shiraz, Iran
}

\begin{abstract}
Both knowledge and attitude can play key roles in the prevention of novel COVID-19. This cross-sectional study was conducted on a statistical sample of pregnant women in southwestern Iran between March and April 2020 to evaluate their knowledge and attitude toward this condition. So, pregnant mothers registered in antenatal clinics affiliated to Shiraz University of Medical Sciences were called and asked to fill in a three-part online questionnaire including sociodemographic characteristics, obstetric/medical history, and knowledge/attitude toward COVID-19. $P$-values $<0.05$ were considered statistically significant. The mean score of knowledge among 540 respondents was $34( \pm 4.1)$ out of 43 . Also, $44.3 \%$ answered more than $80 \%$ of the items correctly. Higher knowledge scores were accordingly associated with marriage duration, area of residence, health insurance coverage, socioeconomic status (SES), and self-rated health status. However, a strong relationship was found between knowledge, SES, and health insurance coverage with reference to multivariate analysis results. Moreover, majority of the pregnant women and their households expressed their concern about using preventive measures against COVID-19. Although most respondents were moderately worried about becoming infected with COVID-19, 264 (48.9\%) cases reported that they were very much anxious about their newborns being infected with COVID-19 and $388(71.9 \%)$ individuals asserted that they were worried about their mortality due to this infection. Besides, most mothers maintained that they had some degrees of rumination, which could interfere with their routine daily chores. Hence, health policy-makers should pay much focus on educating pregnant mothers to help them prevent mental exhaustion.
\end{abstract}

\section{INTRODUCTION}

Infectious diseases can play a significant role in pregnancy, particularly by affecting maternal and fetal outcomes. ${ }^{1}$ Prenatal respiratory infections may also result in stillbirth, miscarriage, and preterm delivery. ${ }^{2}$ Novel COVID-19 is a new respiratory infection that started from Wuhan Province in China and rapidly became widespread in all parts of the world, making the WHO call it "the pandemic of the century." 3,4 Accordingly, patients infected with COVID-19 would experience conditions ranging from a common cold to severe acute respiratory failure. ${ }^{4}$ In addition, no definite medication is still available to prevent or cure this disease, and preventive measures are the only methods to protect people against this infection. 5,6

It is of note that pregnant women are more susceptible to developing severe cases of COVID-19 and consequently being admitted to hospitals and intensive care units because of their physiological changes. ${ }^{7-10}$ Although higher maternal age, presence of comorbidities, and high body mass index have been considered as risk factors for developing severe COVID-19 in expecting mothers. ${ }^{10}$ Moreover, one proven case of transplacental transmission of COVID-19 has been recorded thus far. ${ }^{11}$ SARS also belongs to the same family of COVID-19, with $25 \%$ case fatality rate during pregnancy and various perinatal complications, including disseminated intravascular coagulation, kidney (renal) failure, secondary bacterial pneumonia, sepsis, and abortion. ${ }^{4}$ Besides, the need for mechanical ventilation in pregnant mothers infected with

*Address correspondence to Kamran B. Lankarani, Health Policy Research Center, Shiraz Medical School, Bldg. No. 2, 8th Floor, Zand Ave., Shiraz, Iran 7134845794. E-mail: lankaran@sums.ac.ir
SARS is higher than that for nonpregnant ones. ${ }^{4}$ According to the aforementioned conditions, prevention in the course of this outbreak is very vital for pregnant women. Because both knowledge and attitude can play key roles in prevention of infectious diseases, ${ }^{12}$ the present study was conducted on a statistical sample of pregnant women residing in Shiraz, the fifth populous city located in southwestern Iran, to figure out their knowledge and attitude toward COVID-19.

\section{MATERIALS AND METHODS}

Design and participants. This cross-sectional study, approved by the Ethics Committee affiliated to Shiraz University of Medical Sciences (SUMS) and encoded IR.SUMS.REC. 1398.1424, was fulfilled between March 24, 2020 and April 7, 2020 in the city of Shiraz, Iran. In addition, the Ethical Principles for Medical Research Involving Human Subjects, the World Medical Association Declaration of Helsinki was considered in this study.

For this purpose, pregnant women were recruited in this study if they were Iranian and had been living in the city of Shiraz for at least 6 months before the survey. The databases of all antenatal centers affiliated to SUMS were also used, where the personal information of nearly all mothers who would like to give birth to their babies in governmental hospitals had been registered. The personal information of such pregnant women included their first and last names and landline numbers and/or mobile phone numbers. The secretary of each center then called the pregnant mothers and explained the study and its objectives. Those women who agreed to participate received a link for filling in an online questionnaire. The ones who did not respond to their phones for three times or were unwilling to participate in the study 
were excluded. Approximately, a total number of 920 pregnant women were called, 842 cases agreed to fill in the questionnaire, and 678 mothers checked the site and browsed the questionnaires. Finally, 540 questionnaires were completely answered and submitted.

Data collection instrument. The data collection instrument in this study was an online self-administrated questionnaire, composed of three main parts: sociodemographic characteristics information, obstetric/medical history, and knowledge/ attitude toward COVID-19. The first part of the questionnaire, that is, the sociodemographic information included respondents' date of birth, date of marriage, area of residence (urban versus rural), level of education, occupation (stay-at-home versus employed), health insurance coverage, and socioeconomic status (SES) based on their claims, and perceived correlation between household income and expenditure. The second part of the questionnaire consisted of gestational age (GA), estimated date of delivery, number of pregnancies including the current one, comorbidities, and history of medication use including supplements. The third part was also a 24-item questionnaire to determine levels of knowledge and attitude among pregnant women toward COVID-19. The validity of this part was correspondingly approved by two community medicine specialists, two obstetricians, and one psychologist. The reliability was additionally acceptable (Cronbach's alpha coefficient $=0.9 \%$ ). Cronbach's alpha coefficient for knowledge and attitude were, respectively, $91 \%$ and $85 \%$.

The knowledge domain contained three items to assess the participants' levels of knowledge in terms of the most common manifestations of COVID-19 (Knowledge-Q1), its routes of transmission (Knowledge-Q2), and serious symptoms making infected patients refer to hospitals (Knowledge-Q3). Within the knowledge domain, the respondents could also select many choices as they could think might be correct. Each correct answer was scored one, and each incorrect answer was scored zero. Furthermore, the last choice in each item was "I don't know" which was scored zero. Therefore, the participants could, respectively, achieve scores of 0-14 for Knowledge-Q1, 0-15 for Knowledge-Q2, and 0-14 for Knowledge-Q3. The sum of Knowledge-Q1 to -Q3 was considered as knowledge regarding COVID-19, ranging between 0 and 43. As well, if the participants could obtain a knowledge score higher than 33 out of 43 , used in binary logistic regression analysis, it would be considered as an acceptable level of knowledge.

Another section of the third part of the given questionnaire was a 21-item checklist evaluating the participants' attitude toward COVID-19 in four main areas including preventive measures, concerns, and fears about COVID-19 affecting mothers and/or their newborns, effect of COVID-19 on maternity care, type of delivery and duration of lactation, and impact of quarantine on mothers' mental health. This section was scored through a four-point Likert-type scale, 1 for "not at all," 2 for "somewhat," 3 for "moderately so," and 4 for "very much so." The final attitude score was the sum of scores of all attitude items, ranging between 21 and 84 .

Data analysis. In this study, the data were analyzed using IBM SPSS Statistics software (version 18.0) (IBM Corp., Armonk, NY). The relationship between qualitative variables was further assessed via the chi-square test. To compare numerical variables between two groups, independent samples $t$-test and for the ones among three groups, analysis of variance were used. The variables with $P$-values less than 0.2 in univariate analysis were also entered into the logistic regression model, and backward elimination (alpha-toremove $=0.1$ ) was consequently used. $P$-values less than 0.05 were considered statistically significant.

\section{RESULTS}

A total number of 540 pregnant women participated in this study, with age ranging from 17 to 49 (median $=31$ ) years. The mean duration of their marriage was 7.7 years $( \pm 5.3)$, ranging from 1 to 28 years. Median GA was also 29 (7-40) weeks, and the mean was $27.8( \pm 8.1)$ weeks. As well, mean score for selfrated health status $(\mathrm{SRHS})$ was $6.2( \pm 1.9)$, ranging from 1 to 10 .

Table 1 shows the details of maternal comorbidities and history of medication use. The most common comorbidities were hypothyroidism ( $n=42,7.8 \%)$, diabetes mellitus (DM), and gestational DM $(n=31,5.7 \%)$. On the other hand, one participant $(0.2 \%)$ reported idiopathic thrombocytopenic purpura, as the least reported comorbidity. Regarding the history of medication use by mothers, the most common medication taken by $76(14.1 \%)$ cases was ferrous sulfate and the second one was folic acid ( $n=59,10.9 \%)$. Detailed information in this respect is listed in Table 1.

Table 2 presents the pregnant mothers' knowledge regarding COVID-19. The first item was about the most common symptoms of COVID-19, the mean score of which was 10.8 $( \pm 1.7)$, and a total of $355(65.7 \%)$ participants achieved 11 or higher out of 14 . The second item was associated with routes of transmission. In this item, the mean score was $12.7( \pm 2.6)$, and $438(81.1 \%)$ respondents gained 11 or higher out of 15 , and just one case $(0.2 \%)$ answered less than $30 \%$ of the items correctly. The third item was on the subject of serious symptoms making infected patient refer to hospitals. In this part, the mean score was $10.4( \pm 1.6)$, and $294(54.4 \%)$ participants answered $>70 \%$ of the items correctly. The knowledge score related to COVID-19 (sum of the three previously mentioned knowledge items), ranging from 20 to 41 . The mean score of knowledge was also by $34( \pm 4.1)$, and 239 participants $(44.3 \%)$ answered more than $80 \%$ of the items correctly. As well, 253 pregnant mothers $(46.9 \%)$ had a moderate level of knowledge (correct answer was between $65 \%$ and $80 \%$ ) regarding COVID-19, although none of the participants achieved less than 20 out of 43 .

Table 3 compares the knowledge score regarding COVID19 based on the participants' SES and obstetric/medical

TABLE 1

Pregnant women's comorbidity and medication use history

\begin{tabular}{lrlc}
\hline \multicolumn{1}{c}{ Comorbidity } & $\begin{array}{c}\text { Frequency } \\
(\%)\end{array}$ & \multicolumn{1}{c}{ Medication } & $\begin{array}{c}\text { Frequency } \\
(\%)\end{array}$ \\
\hline Hypothyroidism & $42(7.8)$ & Ferrous sulfate & $76(14.1)$ \\
Diabetes mellitus/GDM & $31(5.7)$ & Folic acid & $59(10.9)$ \\
Other endocrine disorders & $20(3.7)$ & Multi-vitamin & $45(8.3)$ \\
Headache & $19(3.5)$ & Levothyroxine & $42(7.8)$ \\
HTN & $17(3.1)$ & Aspirin & $42(7.8)$ \\
CVD & $9(1.7)$ & Other & $57(10.6)$ \\
Renal diseases & $9(1.7)$ & - & - \\
Respiratory diseases & $7(1.3)$ & - & - \\
Seizure & $7(1.3)$ & - & - \\
Idiopathic & $1(0.2)$ & - & - \\
$\quad$ thrombocytopenic & & & \\
$\quad$ purpura & & & \\
\hline GDM = gestational diabetes mellitus; HTN = hypertension; CVD = cardiovascular diseases.
\end{tabular}


TABLE 2

Pregnant women's knowledge regarding COVID-19

\begin{tabular}{|c|c|c|c|c|}
\hline \multicolumn{5}{|c|}{ Knowledge regarding } \\
\hline \multicolumn{5}{|c|}{ Q1: Most common symptoms of COVID-19* } \\
\hline Mean $( \pm S D)$ & Median (minimum-maximum) & $0-5 f(\%)$ & $6-10 f(\%)$ & $11-14 f(\%)$ \\
\hline $10.8( \pm 1.7)$ & $11(3-14)$ & $4(0.7)$ & $181(33.5)$ & $355(65.7)$ \\
\hline \multicolumn{5}{|c|}{ Q2: Route of transmission of COVID-19† } \\
\hline Mean $( \pm S D)$ & Median (minimum-maximum) & $0-5 f(\%)$ & $6-10 f(\%)$ & $11-15 f(\%)$ \\
\hline $12.7( \pm 2.6)$ & $14(5-15)$ & $1(0.2)$ & $101(18.7)$ & $438(81.1)$ \\
\hline \multicolumn{5}{|c|}{ Q3: Alarming symptoms infected patients with COVID-19 should refer to hospitalł } \\
\hline Mean $( \pm S D)$ & Median (minimum-maximum) & $0-5 f(\%)$ & $6-10 f(\%)$ & $11-14 f(\%)$ \\
\hline $10.4(1.6)$ & $11(3-12)$ & $4(0.7)$ & $242(44.8)$ & $294(54.4)$ \\
\hline \multicolumn{5}{|c|}{ Summary of Q1-Q3: Knowledge regarding COVID-19§ } \\
\hline Mean $( \pm S D)$ & Median (minimum-maximum) & $20-27 f(\%)$ & $28-35 f(\%)$ & $36-43 f(\%)$ \\
\hline $34( \pm 4.1)$ & $35(20-41)$ & 48 (8.9) & $253(46.9)$ & $239(44.3)$ \\
\hline
\end{tabular}

history. Accordingly, the knowledge score was the highest in mothers who had been married for more than 10 years, which was significantly higher than those being married for 5-10 years $(P$-value $=0.02)$. Pregnant women who had been residing in urban areas had also significantly achieved higher knowledge scores than their rural counterparts $(P$-value $=$ 0.001). As well, 52 participants $(9.6 \%)$ were employed; however, the mean score of knowledge was significantly higher in employed individuals than stay-at-home mothers (35 versus 33.9, $P$-value $=0.03$ ). Moreover, 222 pregnant mothers $(41.1 \%)$ had a university degree, who had obtained significantly higher knowledge score regarding COVID-19 than those with lower levels of education $(P$-value $=0.01)$. Most participants had health insurance coverage (435; $80.6 \%)$, and they had significantly higher levels of knowledge than mothers with no insurance coverage $(P$-value $<0.001)$. With reference to the correlation between household income and expenditure, 136 pregnant women $(25.1 \%)$ had reported their income equal to their expenditure, 401 mothers $(74.3 \%)$ had reported their expenditure more than their income, and three cases $(0.6 \%)$ had reported it vice versa. The mean score of knowledge was significantly the highest in cases whose income was more than their expenditure $(P$-value $=0.04)$. Regarding SES, a total number of 242 (44.8\%), 256 (47.4\%), and $42(7.8 \%)$ mothers had asserted that they belonged to low, middle, high SES. There was also a significant difference between the mean score of knowledge in high- and low-SES groups $(P$-value $=0.006)$. The pregnant women had further rated their health status as poor $(n=122,22.6 \%)$, moderate $(n=257$, $47.6 \%)$, and good ( $n=242,44.8 \%)$. It should be noted that the mean score of knowledge was significantly lower in the group with moderate SRHS $(P$-value $=0.03)$.

As shown in Table 4, the results of logistic regression analysis revealed that SES and health insurance coverage were associated with achieving acceptable knowledge scores ( $>33$ out of 43). Therefore, the higher the SES, the higher was the number of participants obtaining acceptable knowledge scores. Moreover, pregnant mothers who had health insurance coverage had 3.4 times higher chance of gaining acceptable knowledge scores $(P$-value $<0.001, \mathrm{Cl}$ for odds ratio: $2.1-5.3)$.

Table 5 illustrates the pregnant women's attitude toward COVID-19. In this regard, majority of the participants reported themselves $(491 ; 90.9 \%)$ and their households $(n=463$, $85.7 \%$ ) were extremely concerned about preventive measures against COVID-19. With regard to being at risk of COVID-19, 74 (13.7\%) mothers had reported "not at all," 249 (46.1\%) cases had reported "somewhat," 140 (25.9\%) individuals had reported "moderately so," and 77 (14.3\%) cases had reported "very much so." Although 43 pregnant women (8\%) were not anxious at all, others had somewhat ( $n=179,33.1 \%)$, moderate ( $n=123,22.8 \%)$, or very much $(n=195,36.1 \%)$ anxiety about being infected with COVID-19. A total number of 264 pregnant women $(48.9 \%)$ were also so much worried about their newborns being infected with COVID-19, whereas 66 $(12.2 \%)$ cases were not worried at all. Most mothers $(n=388$, $71.9 \%$ ) were extremely anxious about their newborns' mortality and morbidity caused by COVID-19, and 480 pregnant women $(88.9 \%)$ had significantly reduced their face-to-face communications. Besides, 271 pregnant mothers $(50.2 \%)$ had reported that their routine prenatal care had been diminished or even discontinued because of closure of antenatal clinics, and 50 (9.3\%) women had continued their routine prenatal care in accordance with the timetable set. On the other hand, stress regarding being infected with COVID-19 had made most mothers ( $n=388,71.9 \%$ ) remarkably reduce or discontinue their routine prenatal care. All the participants had also reported degrees of obsession with washing hands from low ( $n=223,41.3 \%)$ to high $(n=166,30.7 \%)$ degrees. In addition, all the pregnant mothers believed that they had been successful in controlling their stress about COVID-19, but at different levels. Details regarding mothers' attitude toward COVID-19 are shown in Table 5.

\section{DISCUSSION}

In this study, knowledge and attitude toward COVID-19 were evaluated among pregnant women residing in the city of Shiraz, Iran, between March 24 and April 7, 2020. The findings revealed that $70 \%$ of the participants had an acceptable level of knowledge in this regard. Although the highest knowledge score was about routes of transmission of COVID-19, the least score was achieved on serious symptoms making infected patients refer to hospitals. Higher knowledge score was also associated with marriage duration, area of residence (urban versus rural), health insurance coverage, SES, and SRHS. However, a strong relationship was observed between knowledge, SES, and health insurance coverage with reference to multivariate analysis results. 
TABLE 3

Knowledge score based on pregnant women's demographic characteristics and SES

\begin{tabular}{|c|c|c|c|}
\hline \multicolumn{2}{|c|}{ Maternal information } & \multirow{2}{*}{$\frac{\text { Knowledge score }}{\text { Mean ( }(\mathrm{SD})}$} & \multirow[b]{2}{*}{$P$-value } \\
\hline Maternal age (years) & Frequency (\%) & & \\
\hline$<19$ odds ratio $>34$ & $169(31.3)$ & $33.5( \pm 4.5)$ & 0.13 \\
\hline $18<$ age $<35$ & $371(68.7)$ & $34.2( \pm 3.8)$ & \\
\hline \multicolumn{4}{|l|}{ Marriage duration (years) } \\
\hline $1-5$ & $232(43)$ & $34( \pm 3.9)$ & $0.02^{*}$ \\
\hline $6-10$ & $168(31.1)$ & $33.3( \pm 4.4)$ & \\
\hline$>10$ & $140(25.9)$ & $34.6( \pm 3.8)$ & \\
\hline \multicolumn{4}{|l|}{ Number of pregnancies } \\
\hline First pregnancy & $195(36.2)$ & $34( \pm 3.8)$ & 0.9 \\
\hline Second pregnancy & $166(30.7)$ & $34( \pm 4.2)$ & \\
\hline Third or more pregnancy & $179(33.1)$ & $33.9( \pm 4.3)$ & \\
\hline \multicolumn{4}{|l|}{ Gestational age (weeks) } \\
\hline$<14$ & $36(6.7)$ & $33.3( \pm 4.5)$ & 0.7 \\
\hline $14-28$ & $184(34.1)$ & $34.2( \pm 3.9)$ & \\
\hline$>28$ & $320(59.3)$ & $33.9( \pm 4.1)$ & \\
\hline \multicolumn{4}{|l|}{ Area of residence } \\
\hline Urban & $425(78.7)$ & $34.3( \pm 3.9)$ & 0.001 \\
\hline Rural & 115 (21.3) & $32.8( \pm 4.4)$ & \\
\hline \multicolumn{4}{|l|}{ Occupation } \\
\hline Stay-at-home & $488(90.4)$ & $33.9( \pm 4.1)$ & 0.03 \\
\hline Employed & $52(9.6)$ & $35( \pm 3.5)$ & \\
\hline \multicolumn{4}{|l|}{ Highest educational attainment } \\
\hline Below high school diploma & $119(22)$ & $33.1( \pm 4.2)$ & $0.01^{*}$ \\
\hline High school diploma & 199 (36.9) & $33.9( \pm 4.1)$ & \\
\hline University degree & $222(41.1)$ & $34.5( \pm 3.9)$ & \\
\hline \multicolumn{4}{|l|}{ Health insurance coverage } \\
\hline Insured & $435(80.6)$ & $34.4( \pm 3.9)$ & $<0.001$ \\
\hline Noninsured & $105(19.4)$ & $32.3( \pm 4.4)$ & \\
\hline \multicolumn{4}{|c|}{ Correlation between income and expenditure } \\
\hline Equal & $136(25.1)$ & $34.1( \pm 3.9)$ & $0.04 \dagger$ \\
\hline Expenditure $>$ income & 401 (74.3) & $33.9( \pm 4.1)$ & \\
\hline Income $>$ expenditure & $3(0.6)$ & $37.3( \pm 2.5)$ & \\
\hline \multicolumn{4}{|l|}{ Claimed SES } \\
\hline Low & $242(44.8)$ & $33.4( \pm 4.3)$ & $0.006^{\star}$ \\
\hline Middle & $256(47.4)$ & $34.4( \pm 3.8)$ & \\
\hline High & $42(7.8)$ & $34.7( \pm 3.9)$ & \\
\hline \multicolumn{4}{|l|}{$\mathrm{SRH}$} \\
\hline Poor & $122(22.6)$ & $34.9( \pm 4)$ & $0.03 \ddagger$ \\
\hline Moderate & $257(47.6)$ & $33.5( \pm 4.2)$ & \\
\hline Good & $242(44.8)$ & $34.4( \pm 3.8)$ & \\
\hline \multicolumn{4}{|l|}{ Presence of comorbidities } \\
\hline No comorbidity & 452 & $33.9( \pm 4.1)$ & 0.4 \\
\hline One comorbidity & 58 & $34.5(3.2)$ & \\
\hline$>1$ comorbidities & 30 & $34.3( \pm 4.9)$ & \\
\hline
\end{tabular}

* Mean knowledge score was significantly different between the first and the third group.

$\dagger$ Mean knowledge score was significantly different between the third and the first two groups.

$\ddagger$ Mean knowledge score of the second group was significantly different with the other two groups.

In the second part of the study, the findings correspondingly demonstrated that majority of the pregnant mothers and their households were concerned about using preventive measures against COVID-19. Although most respondents were moderately worried about becoming infected with COVID-19,

TABLE 4

Determinants of achieving acceptable knowledge score $>75 \%$ of total score)

\begin{tabular}{lccc}
\hline & OR & $95 \%$ Cl for OR & $P$-value \\
\hline Socioeconomic status & - & - & 0.01 \\
Low & 1 & - & - \\
Intermediate & 1.7 & $1.1-2.5$ & 0.012 \\
High & 2.4 & $1.1-5.8$ & 0.047 \\
Having insurance & & & $<0.001$ \\
No & 1 & - & - \\
Yes & 3.4 & $2.1-5.3$ & $<0.001$ \\
\hline
\end{tabular}

OR = odds ratio. Acceptable knowledge: if score was > 33 (out of 43). about half of them reported that they were very anxious about their newborns being infected with COVID-19, and two-thirds stated that they were worried about their newborns' mortality due to this infection. The mentioned concerns had further made majority of these pregnant mothers reduce or discontinue their routine prenatal care. It should be noted that lack of routine prenatal care might thus increase adverse pregnancy outcomes in various ways. ${ }^{13,14}$ Failure in early detection of abnormal fetuses would additionally lead to loss of the legal window for abortion. No timely diagnosis and treatment of gestational DM and hypertension can also have adverse effects on both maternal and fetal conditions. ${ }^{15}$ In addition, proper assessment of maternal weight gain, following fetal growth, vaccination, timely $\mathrm{Rh}_{\mathrm{o}}(\mathrm{D})$ immune globulin ( $\mathrm{Rh}$ o GAM) shot in special conditions, etc. could be missed in this situation. Besides, most mothers maintained that they had some degrees of rumination, interfering with their routine daily chores. 
TABLE 5

Pregnant women's attitude toward COVID-19

\begin{tabular}{|c|c|c|c|c|c|}
\hline & & Not at all, $f(\%)$ & Somewhat, $f(\%)$ & Moderately so, $f(\%)$ & Very much so, $f(\%)$ \\
\hline A1 & $\begin{array}{l}\text { You are concerned about taking } \\
\text { preventive measures against COVID- } \\
19\end{array}$ & $1(0.2)$ & $3(0.6)$ & $45(8.3)$ & $491(90.9)$ \\
\hline A2 & $\begin{array}{l}\text { Your households are concerned about } \\
\text { taking preventive measures against } \\
\text { COVID-19 }\end{array}$ & $1(0.2)$ & $7(1.3)$ & $69(12.8)$ & $463(85.7)$ \\
\hline A3 & You consider yourself at risk of COVID-19 & 74 (13.7) & $249(46.1)$ & $140(25.9)$ & 77 (14.3) \\
\hline A4 & $\begin{array}{l}\text { You are anxious about being infected with } \\
\text { COVID- } 19\end{array}$ & $43(8)$ & $179(33.1)$ & $123(22.8)$ & $195(36.1)$ \\
\hline A5 & $\begin{array}{l}\text { You are worried about being infected with } \\
\text { COVID-19 during delivery or } \\
\text { postpartum hospital stay }\end{array}$ & $32(5.9)$ & $89(16.5)$ & $100(18.5)$ & $319(59.1)$ \\
\hline A6 & $\begin{array}{l}\text { You are worried about your newborn } \\
\text { being infected with COVID-19 }\end{array}$ & $66(12.2)$ & $132(24.4)$ & $78(14.4)$ & $264(48.9)$ \\
\hline A7 & $\begin{array}{l}\text { You are anxious about your newborn's } \\
\text { mortality by COVID-19 }\end{array}$ & $11(2)$ & $52(9.6)$ & $89(16.5)$ & $388(71.9)$ \\
\hline A8 & $\begin{array}{l}\text { Your routine prenatal care (physical and } \\
\text { para-clinic examinations) has been } \\
\text { reduced or discontinued due to closure } \\
\text { of antenatal clinics }\end{array}$ & $50(9.3)$ & $87(16.1)$ & $132(24.4)$ & $271(50.2)$ \\
\hline A9 & $\begin{array}{l}\text { Stress regarding being infected with } \\
\text { COVID-19 makes you reduce or } \\
\text { discontinue your routine prenatal care } \\
\text { (physical and para-clinic examinations) }\end{array}$ & $24(4.4)$ & $49(9.1)$ & $79(14.6)$ & $388(71.9)$ \\
\hline A10 & $\begin{array}{l}\text { COVID-19 outbreak will affect your type of } \\
\text { delivery (natural, i.e., vaginal delivery or } \\
\text { cesarean section) }\end{array}$ & $85(15.7)$ & $145(26.9)$ & $116(21.5)$ & $194(35.9)$ \\
\hline A11 & $\begin{array}{l}\text { COVID-19 outbreak will negatively affect } \\
\text { your newborn's exclusive } \\
\text { breastfeeding duration }\end{array}$ & $80(14.8)$ & $164(30.4)$ & $123(22.8)$ & $173(32)$ \\
\hline A12 & $\begin{array}{l}\text { Concerns about being infected with } \\
\text { COVID- } 19 \text { have reduced your face-to- } \\
\text { face communications with others }\end{array}$ & $8(1.5)$ & $19(3.5)$ & $33(6.1)$ & $480(88.9)$ \\
\hline A13 & $\begin{array}{l}\text { You receive emotional support from your } \\
\text { households and your social networks }\end{array}$ & 0 & $51(9.4)$ & $100(18.5)$ & 389 (72) \\
\hline A14 & $\begin{array}{l}\text { You follow the news about COVID-19 on } \\
\text { social media }\end{array}$ & 0 & 85 (15.7) & $137(25.4)$ & $318(58.9)$ \\
\hline A15 & $\begin{array}{l}\text { Following news regarding COVID-19 } \\
\text { makes you anxious and upset }\end{array}$ & 0 & $81(15)$ & 147 (27.2) & $312(57.8)$ \\
\hline A16 & $\begin{array}{l}\text { COVID-19 has negatively affected your } \\
\text { routine daily chores }\end{array}$ & 0 & $127(23.5)$ & $223(41.3)$ & $190(35.2)$ \\
\hline A17 & $\begin{array}{l}\text { You are dealing with rumination regarding } \\
\text { COVID- } 19 \text { consequences }\end{array}$ & 0 & $245(45.4)$ & 167 (30.9) & $128(23.7)$ \\
\hline A18 & $\begin{array}{l}\text { You feel obsessed with washing hands } \\
\text { and disinfecting objects }\end{array}$ & 0 & 223 (41.3) & $151(28)$ & $166(30.7)$ \\
\hline A19 & $\begin{array}{l}\text { Home quarantine and social distancing } \\
\text { have negatively affected your mood }\end{array}$ & 0 & $171(31.7)$ & $166(30.7)$ & 203 (37.6) \\
\hline A20 & $\begin{array}{l}\text { Quality and quantity of your sleep have } \\
\text { been negatively affected by COVID-19 }\end{array}$ & 0 & $281(52)$ & 138 (25.6) & $121(22.4)$ \\
\hline A21 & $\begin{array}{l}\text { You have been successful to control your } \\
\text { stress about COVID-19 }\end{array}$ & 0 & 69 (12.8) & 207 (38.3) & 264 (48.9) \\
\hline
\end{tabular}

The results of this study indicated that the overall knowledge regarding COVID-19 was poor in less than $9 \%$ of pregnant women, although about $70 \%$ of the cases achieved acceptable knowledge score. These findings were supported by surveys conducted in different countries, for example, Nigeria, China, the United States, and Bangladesh, suggesting that pregnant women had acceptable levels of knowledge of COVID-19. ${ }^{16-19}$ This could be the result of efforts made by governmental and nongovernmental organizations aimed to educate people through various methods including social media, newspapers, television programs, and short message services. However, these findings were not universal as Sirchan et al. ${ }^{20}$ had reported that most Thai women $(74.1 \%)$ had poor knowledge about COVID-19.
Talking about knowledge, the highest knowledge score was found for routes of transmission of COVID-19, which had been correctly answered by more than $80 \%$ of the pregnant mothers. These findings were consistent with the results of the study by Farhanan and Mannan ${ }^{17}$ in which most Bangladeshi women had adequate knowledge about routes of transmission of COVID-19. This high level of knowledge can be considered as an advantageous point because it can lead people to take proper preventive measures. Besides, about two-thirds of the participants in the present study had acceptable knowledge regarding the most common manifestations of COVID-19. Having an acceptable level of knowledge regarding common symptoms of this condition can help people become aware of common symptoms of diseases and 
on-time referrals to healthcare centers and hospitals, hence not infect unaffected individuals. Nevertheless, this domain needs special attention because it can act as a double-edged sword. If people refer to hospitals for any unimportant manifestations of COVID-19, it can result in burnout among healthcare workers. On the other hand, referring late to hospitals can give rise to higher rate of severe cases and even higher mortality rates.

Similar to the findings of the present study, Rahman and Sathi ${ }^{21}$ and Abdelhafiz et al. $^{22}$ had revealed that individuals living in urban areas had more knowledge about COVID-19. This could be because of more access to information technologies. The given results were further supported by other surveys that had shown that occupation, ${ }^{18,19,21}$ level of education, ${ }^{18,19,21}$ and area of residence ${ }^{18}$ were predictors of knowledge score; hence, people with lower levels of education and unemployment had gained lower knowledge score. ${ }^{18,19,21}$ With reference to occupation, higher knowledge score could be because of more connections with other people, so there were more concerns about the virus, discussions about it with colleagues, and attempts to get more knowledge to protect themselves and their family. Moreover, Abdelhafiz et al. ${ }^{22}$ had demonstrated a direct correlation between knowledge score and income as reported in the present study. Based on logistic regression analysis results, SES and health insurance coverage could have significant roles in achieving acceptable knowledge score. This may happen as people with higher SES are supposed to have more access to information devices and have larger social networks. Besides, they generally have higher levels of education than those in lower SES groups. ${ }^{23}$ All things together may lead to having more knowledge about COVID-19 in individuals with higher SES. On the other hand, health insurance coverage in Iran is somehow related to SES. Based on insurance policy in Iran, an individual can have insurance through different methods. The most common method is being insured by employers either in governmental or in private sectors. ${ }^{24}$ Similarly, people who are self-employed can insure themselves by paying the premium on a monthly basis. ${ }^{24}$ In addition, stay-at-home individuals can insure themselves if they pay insurance fees and charges themselves. ${ }^{24}$ Accordingly, people with health insurance coverage can have more stable income, and this can lead to higher levels of education and access to more information technologies. Therefore, individuals benefiting from insurance can get more information about COVID-19 and reach acceptable knowledge score about it.

The study findings additionally showed that majority of the participants and their households were very much concerned about the preventive measures against COVID-19, in line with the results reported by Yassa et al. ${ }^{25}$ in which most Turkish pregnant women had taken adequate precautions against COVID-19. Furthermore, most participants in the present study maintained they that had reduced face-to-face communications, supported by results of the survey by Corbett et al. ${ }^{26}$ in Ireland. These findings also reflected on pregnant mothers' attention to preventive instructions, which could be rooted in their higher degrees of concerns toward their own health status and that of their newborns.

The present study revealed that most pregnant women had reported various degrees of worry about becoming infected with COVID-19, consistent with the findings from two other surveys on COVID-19 among pregnant mothers residing in
Shanghai, China, and in Istanbul, Turkey. ${ }^{25,27}$ The study findings also showed that most participants had moderate to high concerns about being infected with COVID-19 during delivery or postpartum hospital stay, far more than pregnant women in Istanbul, in which one-third of the participants had mentioned it as a hard situation. ${ }^{25}$

In contradiction of the present study in which majority of the participants were worried about their newborns' infection with COVID-19, Yassa et al. ${ }^{25}$ had reported that less than half of pregnant mothers had this concern. However, concern regarding newborns' mortality due to COVID-19 was relatively similar to that in the present study and in Corbett's in Ireland. ${ }^{26}$ The high degree of concern toward morbidity and mortality associated with COVID-19 might be derived from a low global data about the nature of COVID-19 and lack of promising medical treatments.

In terms of prenatal care, three-quarters of the pregnant women in the present study reiterated that their routine prenatal care had been reduced or discontinued. The reasons were mothers' concerns about becoming infected with COVID-19, as well as closure of antenatal clinics for nearly 2 months from March to April. Likewise, a study in Shanghai had reported that pregnant women, especially in the second trimester, were more willing to cut down the frequency of prenatal care and over $85 \%$ of the participants, particularly the primiparous ones, had requested online consultations to avoid being present in crowded places. ${ }^{27}$ This pointed to the participants' knowledge and concerns regarding the routes of transmission of COVID-19, which could be through direct encounters with infected patients in crowded places or via contacts with infected surfaces.

Concerning the effect of COVID-19 on pregnant women's mental health status, the study findings revealed that none of the participants was negligent regarding COVID-19 and its consequences. Although the degree of worry was different among the respondents, these negative thoughts had affected about one-third of Turkish pregnant women in Yassa's survey. ${ }^{25}$ Moreover, similar to the results of the present study in which the outbreak had a detrimental effect on moods of most pregnant mothers, a cohort study in China had found an increasing trend in the prevalence of perinatal depression following the current outbreak. ${ }^{28}$ According to these findings, pregnant mothers were suffering from the mental burden of the COVID-19 pandemic because they would have been concerned about their own health status and that of their newborns.

Among the weaknesses of the present study was no access to participants from other provinces in Iran. Because Shiraz was one of the cities whose residents were following social distancing rules more strictly, the results cannot be also generalized to the whole country. In addition, the questionnaire was a self-administered online one, which needed more patience than those filled through face-to-face interviews. Therefore, some participants who checked the site link but not finished the survey were missed.

One of the most prominent strengths of this study was the time it was implemented. In fact, the present study was conducted when COVID-19 was at its peak in Iran. Moreover, a self-administered questionnaire was used in the present study by which pregnant women could feel more comfortable to complete it on their free time, which increased the accuracy of the answers. 
In sum, although majority of the pregnant women in this study had an acceptable level of knowledge regarding the routes of transmission and serious symptoms of COVID-19, the lowest knowledge score was on serious symptoms making infected patients with COVID-19 refer to hospitals. Hence, health policy-makers should lay much focus on educating people regarding situations in which infected patients including pregnant mothers should refer to hospitals. In fact, unnecessary referrals would lead to burnout among healthcare workers, whereas late referrals would result in higher rates of morbidities and mortalities as well as increased expenditure imposed on healthcare systems. Besides, a strong correlation was found between the participants' knowledge score and higher SES, which implicitly denoted the necessity of special attention to educating lower SES groups through different methods. Furthermore, the study participants had a remarkable worry regarding becoming infected with COVID19, which could interfere with their routine daily chores. Therefore, more information should be given to pregnant mothers to prevent them from becoming mentally exhausted.

Received June 6, 2020. Accepted for publication October 18, 2020.

Published online October 27, 2020.

Acknowledgments: We would like to extend our gratitude to the Vice Chancellor's Office for Research at Shiraz University of Medical Sciences, Shiraz, Iran, for financially supporting the project. We also thank all staff in the healthcare centers and pregnant mothers who participated in this study. Publication charges for this article were waived due to the ongoing pandemic of COVID-19.

Financial support: This study was financially supported by the Vice Chancellor's Office for Research at Shiraz University of Medical Sciences, Shiraz, Iran.

Authors' addresses: Najmeh Maharlouei, Mohammad-hassan Zahedroozegar, Fatemeh Shaygani, Behnam Honarvar, Camellia Hemyari, Marziyeh Zare, and Kamran B. Lankarani, Health Policy Research Center, Institute of Health, Shiraz University of Medical Sciences, Shiraz, Iran, E-mails: najmeh.maharlouei@gmail.com, zahedmohammad05@ gmail.com, shaygani.f@gmail.com, honavarbh32@yahoo.com, camellia. hemyari@gmail.com, marziyeh.zare70@gmail.com, and lankaran@ sums.ac.ir. Nasrin Asadi, Khadijeh Bazrafshan, and Shohreh Roozmeh, Maternal-Fetal Medicine Research Center, Shiraz University of Medical Sciences, Shiraz, Iran, E-mails: nasadi2012@outlook.com, bazrafshan.kh@gmail.com, and dr.roozmeh1995@yahoo.com. Abbas Rezaianzadeh, Colorectal Research Center, Shiraz University of Medical Sciences, Shiraz, Iran, E-mail: rezaiana@gmail.com. Ali Kharmandar, Health Policy Research Center, Shiraz University of Medical Sciences, Shiraz, Iran, and Non-Communicable Disease Research Center, Fasa University of Medical Sciences, Fasa, Iran, E-mail: ali.kh.sampad@ gmail.com. Navid Omidifar, Department of Pathology, Medical Education Research Center, Shiraz University of Medical Sciences, Shiraz, Iran, E-mail: omidifar@gmail.com.

This is an open-access article distributed under the terms of the Creative Commons Attribution (CC-BY) License, which permits unrestricted use, distribution, and reproduction in any medium, provided the original author and source are credited.

\section{REFERENCES}

1. Adinolfi M, 1993. Infectious diseases in pregnancy, cytokines and neurological impairment: an hypothesis. Dev Med Child Neurol 35: 549-553.

2. Englund JA, Chu HY, 2018. Respiratory virus infection during pregnancy: does it matter? J Infect Dis 218: 512-515.

3. World Health Organization, 2020. Situation Reports. Geneva, Switzerland: WHO. Available at: https://www.who.int/emergencies/ diseases/novel-coronavirus-2019/situation-reports/. Accessed February 5, 2020.
4. Rasmussen SA, Smulian JC, Lednicky JA, Wen TS, Jamieson DJ, 2020. Coronavirus disease 2019 (COVID-19) and pregnancy: what obstetricians need to know. Am J Obstet Gynecol 222: 415-426.

5. World Health Organization, 2020. Myth Busters. Geneva, Switzerland: WHO. Available at: https://www.who.int/images/ default-source/health-topics/coronavirus/myth-busters/webmythbusters/mythbuster-4.png?sfvrsn=e163bada_8. Accessed February 5, 2020.

6. World Health Organization, 2020. Q\&A on Coronaviruses (COVID-19). Geneva, Switzerland: WHO. Available at: https://www.who.int/ news-room/q-a-detail/q-a-coronaviruses. Accessed February 5, 2020.

7. Liu H, Wang LL, Zhao SJ, Kwak-Kim J, Mor G, Liao A, 2020. Why are pregnant women susceptible to viral infection: an immunological viewpoint? J Reprod Immunol 139: 103122.

8. Centers for Disease Control and Prevention, 2020. Characteristics of Women of Reproductive Age with Laboratory-Confirmed SARS-CoV-2 Infection by Pregnancy Status - United States, January 22-June 7, 2020. Available at: https://www.cdc.gov/ $\mathrm{mmwr} /$ volumes/69/wr/mm6925a1.htm. Accessed July 26, 2020.

9. Dashraath P, Wong JLJ, Lim MXK, Lim LM, Li S, Biswas A, Choolani M, Mattar C, Su LL, 2020. Coronavirus disease 2019 (COVID-19) pandemic and pregnancy. Am J Obstet Gynecol 222: $521-531$.

10. Allotey $\mathrm{J}$ et al., 2020. Clinical manifestations, risk factors, and maternal and perinatal outcomes of coronavirus disease 2019 in pregnancy: living systematic review and meta-analysis. $B M J$ 370: $\mathrm{m} 3320$.

11. Vivanti AJ, Vauloup-Fellous $C$, Prevot $S$, Zupan V, Suffee C, Do Cao J, Benachi A, De Luca D, 2020. Transplacental transmission of SARS-CoV-2 infection. Nat Commun 11: 3572.

12. Swaddiwudhipong $W$, Lerdlukanavonge $P$, Khumklam $P$, Koonchote S, Nguntra P, Chaovakiratipong C, 1992. A survey of knowledge, attitude and practice of the prevention of dengue hemorrhagic fever in an urban community of Thailand. Southeast Asian J Trop Med Public Health 23: 207-211.

13. Coxon K, Turienzo CF, Kweekel L, Goodarzi B, Brigante L, Simon A, Lanau MM, 2020. The impact of the coronavirus (COVID-19) pandemic on maternity care in Europe. Midwifery 88: 102779.

14. Liu CM, Chang SD, Cheng PJ, 2012. Relationship between prenatal care and maternal complications in women with preeclampsia: implications for continuity and discontinuity of prenatal care. Taiwanese J Obstet Gynecol 51: 576-582.

15. Carter EB, Tuuli MG, Odibo AO, Macones GA, Cahill AG, 2017. Prenatal visit utilization and outcomes in pregnant women with type II and gestational diabetes. J Perinatol 37: 122-126.

16. Clements JM, 2020. Knowledge and behaviors toward COVID-19 among US residents during the early days of the pandemic: cross-sectional online questionnaire. JMIR Public Health Surveill 6: e19161.

17. Farhana M, Mannan D, 2020. Knowledge and perception towards novel coronavirus (COVID 19) in Bangladesh. Int Res J Business Soc Sci 6: 76-87.

18. Nwafor Jl, Aniukwu JK, Anozie BO, Ikeotuonye AC, Okedo-Alex IN, 2020. Pregnant women's knowledge and practice of preventive measures against COVID-19 in a low-resource African setting. Int J Gynaecol Obstet 150: 121-123.

19. Zhong BL, Luo W, Li HM, Zhang QQ, Liu XG, Li WT, Li Y, 2020. Knowledge, attitudes, and practices towards COVID-19 among Chinese residents during the rapid rise period of the COVID-19 outbreak: a quick online cross-sectional survey. Int J Biol Sci 16: $1745-1752$.

20. Srichan $P$, Apidechkul T, Tamornpark R, Yeemard F, Khunthason S, Kitchanapaiboon S, Wongnuch P, Wongphaet A, Upala P, 2020. Knowledge, attitude and preparedness to respond to the 2019 novel coronavirus (COVID-19) among the bordered population of northern Thailand in the early period of the outbreak: a cross-sectional study. WHO South East Asia J Public Health 9: 118-125.

21. Rahman A, Sathi N, 2020. Knowledge, attitude, and preventive practices toward COVID-19 among Bangladeshi internet users electronic J Gen Med, 17: em245. 
22. Abdelhafiz AS, Mohammed Z, Ibrahim ME, Ziady HH, Alorabi M, Ayyad M, Sultan EA, 2020. Knowledge, perceptions, and attitude of Egyptians towards the novel coronavirus disease (COVID-19). J Commun Health 45: 881-890.

23. Meagan Sweeney M, 2015. Stop Skipping Class: Why Socioeconomic Status (SES) Matters. Available at: https://www.apa.org/pi/ses/ resources/indicator/2015/09/socioeconomic-status. Accessed May 20, 2020.

24. Ministry of Coopratives, 2020. Ministry of Cooperatives, labour and social welfare Work and insurance law. Available at: https:// www.mcls.gov.ir/fa/rahnamayemorajein/karegaran-\% D9\%82\%D9\%88\%D8\%A7\%D9\%86\%DB\%8C\%D9\%86-\% D9\%85\%D8\%B1\%D8\%AA\%D8\%A8\%D8\%B7-\%D8\%A8\% D8\%A7-\%DA\%A9\%D8\%A7\%D8\%B1\%DA\%AF\%D8\%B1\% D8\%A7\%D9\%86. Accessed May 20, 2020.
25. Yassa M, Birol P, Yirmibes C, Usta C, Haydar A, Yassa A, Sandal $K$, Tekin AB, Tug N, 2020. Near-term pregnant women's attitude toward, concern about and knowledge of the COVID-19 pandemic. J Maternal-Fetal Neonatal Med 33: 3827-3834.

26. Corbett GA, Milne SJ, Hehir MP, Lindow SW, O'Connell MP, 2020. Health anxiety and behavioural changes of pregnant women during the COVID-19 pandemic. Eur J Obstet Gynecol Reprod Biol 249: 96-97.

27. Du L, Gu YB, Cui MQ, Li WX, Wang J, Zhu LP, Xu B, 2020. Investigation on demands for antenatal care services among 2 002 pregnant women during the epidemic of COVID-19 in Shanghai. Zhonghua Fu Chan Ke Za Zhi 55: 160-165.

28. Wu YT et al., 2020. Perinatal depression of women along with 2019 novel coronavirus breakout in China. SSRN Electron J (Epub ahead of print). Available at: https://doi.org/10.1016/ j.ajog.2020.05.009. 